ANALYSIS OF MEASUREMENT UNCERTAINTIES IN THE NULLING TEST FOR AIR LEAKAGE FROM RESIDENTIAL DUCTS

JOHN W. ANDREWS

APRIL 2001

Prepared for:

Office of Building Technologies

State and Community Programs

U.S. Department of Energy

Washington, DC 20585

Under Contract No. DE-AC02-98CH10886 


\section{DISCLAIMER}

- This report was prepared as an account of work sponsored by an agency of the United States Government. Neither the United States Government nor any agency thereof, nor any of their employees, nor any of their contractors, subcontractors, or their employees makes any warranty, express or implied, or assumes any legal liability or responsibility for the accuracy, completeness, or usefulness of any information, apparatus, product or process disclosed, or represents that its use would not infringe privately owned rights. Reference herein to any specific commercial product, process, or service by trade name, trademark manufacturer, or otherwise, does not necessarily constitute or imply its endorsement, recommendation, or favoring by the United States Government or any agency thereof. The views and opinions of authors expressed herein do not necessarily state or reflect those of the United States Government or any agency, contractor, or subcontractor thereof. 


\section{TABLE OF CONTENTS}

\section{Page}

EXECUTIVE SUMMARY

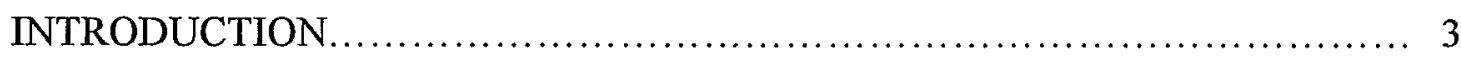

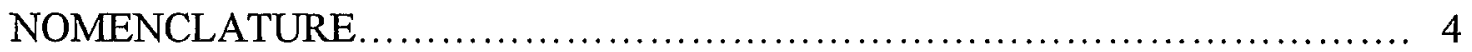

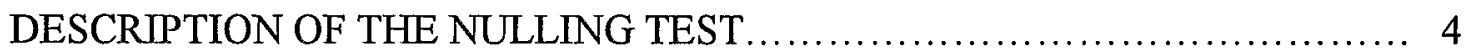

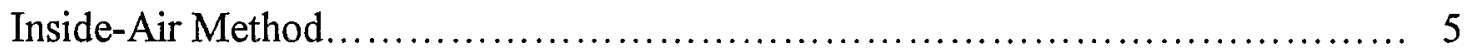

Outside-Air Method...................................................... 5

ACCURACY DEPENDS ON ENVELOPE TIGHTNESS ...................... 6

FIRST PART OF NULLING TEST: MEASUREMENT OF UNBALANCED

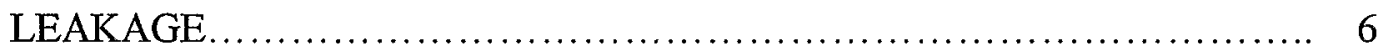

SECOND PART OF THE NULLING TEST: MEASURING THE SUPPLY

LEAKAGE

Inside-Air Method $\ldots \ldots \ldots \ldots \ldots \ldots \ldots \ldots \ldots \ldots \ldots \ldots \ldots \ldots \ldots \ldots \ldots \ldots, 12$

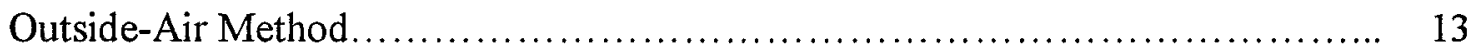

BENCHMARKING THE UNCERTAINTIES ................................ 14

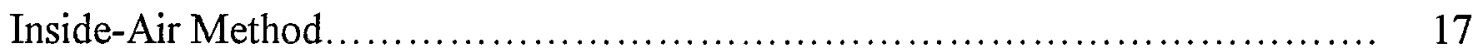

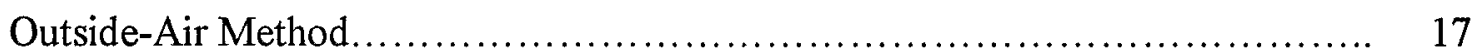

COMPARISON WITH EXPERIMENTAL DATA .......................... 18

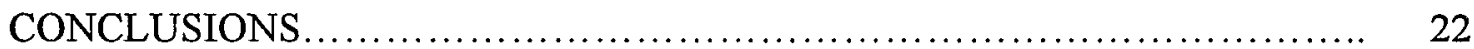

POSSIBLE FURTHER DEVELOPMENT OF THE NULLING TEST .......... 22

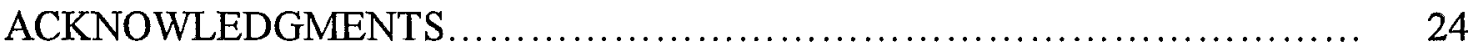

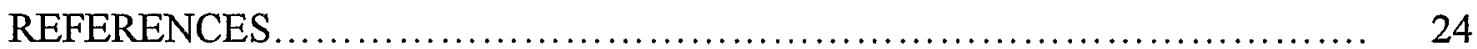




\section{LIST OF TABLES}

$\underline{\text { Page }}$

Table 1. Values of the coefficient in Equation 11 for $n_{\text {env }}=0.65 \ldots \ldots \ldots \ldots \ldots \ldots$

Table 2. Values of $1.5\left(\mathrm{C}_{\text {env }}\right)^{2}(\mathrm{errP})^{2 \text { 2nenv }}$ for benchmark values of envelope....... 16

Table 3. Uncertainties in supply leakage (errQ $\mathrm{estak}_{\text {) }}$ ) for the inside-air method, using Equation 17 for selected values of envelope and measurement uncertainty of pressures and air-flows.................................

Table 4. Uncertainties in return leakage (err $\mathrm{Qrleak}_{\text {) }}$ ) for the inside-air method, Using Equation 19 for selected values of envelope leakage and Measurement uncertainty of pressures and air-flows

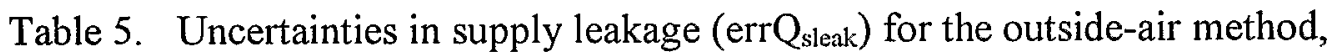
using Equation 17 for selected values of envelope and measurement uncertainty of pressures and air-flows................................

Table 6. Uncertainties in return leakage (errQ rleak) for the outside-air method, Using Equation 19 for selected values of envelope leakage and Measurement uncertainty of pressures and air-flows....

Table 7. Deviations of Nulling Test from "Best Estimate" from Francisco And Palmiter 1999

Table 8. Deviations of Nulling Test from "Best Estimate" from Cummings And Withers 1999

\section{LIST OF FIGURES}




\title{
ANALYSIS OF MEASUREMENT UNCERTAINTIES IN THE NULLING TEST FOR AIR LEAKAGE FROM RESIDENTIAL DUCTS
}

\author{
John W. Andrews \\ Brookhaven National Laboratory \\ Upton, NY 11973
}

jwandrews@bnl.gov

April, 2000

\begin{abstract}
An analysis of measurement uncertainties in a recently proposed method of measuring air leakage in residential duct systems has been carried out. The uncertainties in supply and return leakage rates are expressed in terms of the value of the envelope leakage flow coefficient and the uncertainties in measured pressures and air flow rates. Results of the analysis are compared with data published by two research groups.
\end{abstract}




\section{EXECUTIVE SUMMMARY}

This report discusses an analysis of experimental uncertainties in a new test for air leakage from residential duct systems. The test, called the nulling test because it uses an adjustable-speed fan to zero out or "null" the difference between two measured pressures, was proposed in 1999 by researchers at Ecotope, Inc., in Seattle.

The test uses a calibrated fan/flowmeter (blower door or duct blower) to match the pressure in the house with the system fan on to a target value measured with the system fan off. With the duct system in its as-found condition, the flow rate through the fan/ flowmeter is then equal to the unbalanced duct leakage (supply leakage to outside minus return leakage from outside). By blocking off the return portion of the system and using a second fan/flowmeter to feed the supply side of the duct system, the same technique can be used to measure the supply leakage separately. The return leakage is then calculated as the difference between the supply leakage (a positive number) and the unbalanced leakage (which can be positive, negative, or zero).

The measurement of supply leakage can be carried out in two different ways. In one of these (the "inside-air method") the air supplied to the second fan/flowmeter is taken from the conditioned space via a temporary duct. In the alternative procedure (the "outside-air method") the second fan/flowmeter takes its air from its immediate surroundings, which in a well-vented buffer space means it comes from the outside. The outside-air method is easier to do, but it is expected to be less accurate because it obtains the supply leakage as a difference between two larger air flows that are not greatly different in percentage terms. Small fractional uncertainties in each of two nearly-equal quantities can lead to a large fractional uncertainty in their difference.

One advantage of the nulling technique is that the value of the envelope leakage flow coefficient does not enter into the calculation, as it does for a conceptually similar test called the house pressure test that is currently in ASHRAE Standard 152P. Another advantage is that the neutralpressure level is kept the same throughout the test. As a consequence, the nulling test does not a depend on some mathematical assumptions that have been questioned in the house pressure test. The Ecotope group also found, in some field trials, that the nulling test fared better than other duct leakage tests in a comparison of measured values with "best estimate" values that they had reason to believe were quite close to the actual duct leakage rates.

However, despite the fact that the duct leakage rates calculated from the nulling test do not depend on the value of the envelope leakage flow coefficient, the accuracy of the nulling test does depend on this coefficient. The nulling test will be less accurate in a leaky house than in a tight one, for the reason that, given any specific tolerance for how closely the fan-on and fan-off pressures in the house are matched, the range of air flow rates that meet this tolerance will be wider if the envelope is leaky than if it is tight. In the limit of a very leaky envelope (open windows and doors), the pressures will match regardless of what is done with the fan/flowmeter and we will have no information at all about duct leakage rates. 
This report derives equations for the experimental uncertainties in the supply and return leakage rates in terms of the value of the envelope leakage flow coefficient, the uncertainties in the measured flow rates, and another uncertainty reflecting how closely the house pressure with the system fan on can be matched to the value with the system fan off.

The major conclusion is that, except for very tight envelopes, experimental uncertainties in the nulling test will be controlled by how leaky the house envelope is and by how precisely the house pressures can be matched, and not by the accuracy of the air-flow measurements.

The above statement applies to the inside-air method. The outside-air method adds two significant additional sources of error: the uncertainty in the system fan flow rate and a greatly increased uncertainty in the air flow rate across the envelope during the second part of the test that measures supply leakage.

The expected uncertainties in the supply and return leakage rates were benchmarked in terms of uncertainties in the directly-measured quantities (e.g., pressures, flow rates) derived from field experience and manufacturer's specifications. For example, a house with an envelope CFM50 of $\sim 2500$ and assuming a $0.2 \mathrm{~Pa}$ uncertainty in pressure measurements, a one-standard-deviation uncertainty using the inside-air method is on the supply side and $\pm 126 \mathrm{cfm}$ on the return side. Tightening the envelope to 1250 CFM50 and the pressure-measurement uncertainty to $0.1 \mathrm{~Pa}$ reduces these leakage uncertainties to $\pm 29 \mathrm{cfm}$ and $\pm 40 \mathrm{cfm}$, respectively.

The calculated uncertainties are broadly consistent with those extracted from the limited field data currently available. However, the expected greater uncertainty in the return leakage (as compared with the uncertainty in the supply leakage) was not seen in the comparison of the referenced data with the researchers' "best estimate" duct leakage values. It is not known to what extent this is due to: a) statistical fluctuation; b) an artifact of the procedures used by the referenced experimenters in choosing their "best estimate" duct leakage rates for comparison; or c) some significant factor that was not captured in this analysis.

Except for the case of well-controlled pressure matching in very tight envelopes, the calculated uncertainties (even in the inside-air method) are sufficiently large to warrant a search for ways to reduce them. There is a need for further field work on the test, to assess the magnitude of the uncertainties, to compare these with theoretical analyses such as this one, and to determine whether the uncertainties in the nulling test can be reduced in any practical way.

Some suggestions have been provided for further work on enhancing the accuracy of the nulling test. These involve various plans for adding an additional piece of data to serve as a "crosscheck" on the nulling-test results, and a possible procedure for tightening the tolerance limit on the pressure matching that is at the heart of the test. 


\section{INTRODUCTION}

Recently, a group of researchers based in Seattle proposed a new test to measure air leakage rates in residential duct systems (Francisco and Palmiter 1999). The test, which they have called the "nulling test," is based on matching the pressure in the house with the system fan on to a target value measured with the system fan off. The matching is achieved by using a calibrated fan/flowmeter (either a blower door or a duct blower) to blow air into or out of the house at a rate sufficient to adjust the pressure within the house back to what it was when the system fan was off. With the duct system in its as-found condition, the flow rate through the fan/flowmeter is then equal to the unbalanced duct leakage (supply leakage to outside minus return leakage from outside). By blocking off the return portion of the system and making some other changes, the same technique can be used to measure the supply leakage separately. The return leakage is then calculated as the difference between the supply leakage (a positive number) and the unbalanced leakage (which might be positive, negative, or zero).

One advantage claimed for this "nulling" technique is that the value of the envelope leakage flow coefficient does not enter into the calculation, as it does for a conceptually similar test called the house pressure test that is currently in Standard 152P of the American Society of Heating, Refrigerating, and Air Conditioning Engineers (ASHRAE 1999). Another advantage is that the air infiltration regime is not altered in the nulling test. That is, the neutral level is kept the same during the air flow test that it is during the fan-off house pressure measurement.

These factors remove a dependence on mathematical assumptions that have been questioned in the house pressure test. Francisco and Palmiter also found, in some tests of a preliminary nature, that the nulling test fared better than other duct leakage tests in a comparison of measured values with "best estimate" values that they had reason to believe were quite close to the actual duct leakage rates.

In view of this initial promise, it seemed appropriate to perform an analysis of the measurement uncertainties of the nulling test. The objectives of this analysis were, first, to quantify expected uncertainties in measured values of supply and return leakage, and second, to determine whether any practical steps might be available to reduce these errors consistent with reasonable economy of effort. This report discusses the derivation and results of this analysis, compares it with two available sources of data, and makes suggestions on how the accuracy of the nulling test might be enhanced. 


\section{NOMENCLATURE}

The following terminology is used in the report without further definition. Unless otherwise stated, it is assumed that air-flow rates will be measured in cubic feet per minute (cfm) and that pressures will be measured in pascals $(\mathrm{Pa}$ ). (One pascal is equal to one newton per square meter or 0.004 inches of water column.)

P Measured house pressure (pressure in the conditioned space, with respect to the outside), intended to equal the null pressure $P_{0}$.

$P_{0} \quad$ The "null pressure" or target pressure, measured with the system fan off, to which the house pressure is returned (using a fan/flowmeter) when the system fan is turned on.

$\mathrm{Q}_{\mathrm{bd}} \quad$ Air flow rate across the envelope ( + for flow into house) during the measurement of unbalanced leakage. The "bd" subscript stands for "blower door," but it is understood that the measurement may actually be made with a smaller version of the blower door, often referred to by a common trade name "duct blaster," but here termed (generically) a duct blower.

$\mathrm{Q}_{\mathrm{bd}, \mathrm{s}} \quad$ Air flow rate across the envelope (+ for flow into house) during the measurement of supply leakage.

$\mathrm{Q}_{\text {del }} \quad$ Air flow rate delivered to the living space by the supply duct system.

$\mathrm{Q}_{\mathrm{env}} \quad$ Net air leakage into the building envelope ( + for net inward leakage).

$\mathrm{Q}_{\text {rleak }} \quad$ Return duct leakage from outside under normal operating conditions.

$\mathrm{Q}_{\text {steak }} \quad$ Supply duct leakage to outside under normal operating conditions.

(Note: Both $\mathrm{Q}_{\text {sleak }}$ and $\mathrm{Q}_{\text {rleak }}$ are defined to be positive quantities under normal conditions of outward supply leakage and inward return leakage.)

$\mathrm{Q}_{\text {seakk+rleak }} \quad$ Algebraic difference of supply leakage minus return leakage as measured directly in the first part of the nulling test. (Might not equal $Q_{\text {sleak }}-Q_{\text {rleak }}$ due to measurement errors.)

\section{DESCRIPTION OF THE NULLING TEST}

As summarized in the Introduction, the nulling test has two distinct parts. The first part measures the unbalanced leakage $\left(\mathrm{Q}_{\text {sleaktrleak }}\right)$ and the second part measures the supply-side leakage $\left(\mathrm{Q}_{\text {sleak }}\right)$. The return side leakage $\left(Q_{\text {rleak }}\right)$ is then calculated using $Q_{\text {rleak }}=Q_{\text {sleak }}-Q_{\text {sleaktrleak }}$.

The experimental setup for the first part of the nulling test is shown in Figure 1. In Part 1, the pressure in the living space with respect to the outside is measured with the system fan off. The system fan is then turned on, and a fan/flowmeter (blower door or duct blower) mounted in an outside doorway or window opening is turned on and adjusted until the house pressure is the same as it was with the system fan off. The air flow rate through the fan/flowmeter is then read off and set equal to the unbalanced duct leakage $\left(Q_{\text {sleak }+ \text { rleak }}\right)$. If the air flow is into the envelope, it means that the supply leakage exceeds the return leakage $\left(Q_{\text {sleak+rleak }}>0\right)$ while if the air flow is to the outside, the return leakage dominates $\left(\mathrm{Q}_{\text {sleak }+ \text { rleak }}<0\right)$. 
The second part of the test requires some preliminary steps. First, with the system fan on but the fan/flowmeter off and covered, the static pressure (with respect to the living space) is measured at some point in the supply duct, at or near the plenum. Next, an air-tight barrier is installed in the return duct at the point where it enters the air handler. Finally, a second fan/flowmeter is installed in such a manner that it can blow air into the air handler downstream of the barrier and upstream of the system fan.

\section{Inside-Air Method}

There are two alternative procedures for the second part of the nulling test, called the inside-air method and the outside-air method. The inside-air method is expected to be the more accurate of the two. This method requires that the air to the second fan/flowmeter be supplied from the living space. This is easy if the air handler is inside the living space, but usually it isn't. In that case, it is necessary to run a temporary duct from the living space to a duct blower attached at the fanaccess opening of the air handler, as shown in the bottom half of Figure 1. Any region surrounding the temporary duct, at the point where it penetrates the envelope and at the point of attachment to the duct blower, must be sealed to ensure that all the air, and only that air, which is taken from the living space passes through the duct blower.

Another possibility, if the space containing the air handler is separated from the living space by a doorway (e.g., if the air handler is in a garage or basement) would be to install a blower door in that doorway and run a length of flexible duct from the outlet side of the blower door to the fan access opening of the air handler.

Under these circumstances, it will always be necessary to orient the first fan/flowmeter in the direction that will blow air into the living space, and the flow rate through this device will equal the supply leakage $\mathrm{Q}_{\text {sleak }}$.

Using the example flow rates shown in Figure $1, Q_{\text {sleak+rleak }}=-100 \mathrm{cfm}$ (minus because the air is blowing out) and $Q_{\text {sleak }}=150 \mathrm{cfm}$. This implies that $Q_{\text {rleak }}=150-(-100)=250 \mathrm{cfm}$.

\section{Outside-Air Method}

The alternative procedure for the second part of the nulling test is the outside-air method. In this procedure the dedicated air path from the living space to the air handler is omitted. The second fan/flowmeter, which in this case must be mounted at the air handler and not at the interface between the living space and the duct zone, gets its air from the space surrounding the ducts. If this space is well vented, the air is effectively taken from the outside.

The outside-air method is expected to be less accurate than the inside air method for the following reason. In the inside-air method, the first fan/flowmeter measures $\mathrm{Q}_{\text {sleak }}$ directly. In the outsideair method, however, what is measured is the delivered air flow rate $Q_{\text {del }}$, which is system fan flow rate minus the supply leakage $\left(Q_{e}-Q_{\text {steak }}\right)$. It is then necessary to subtract this from the measured system fan flow rate $\left(Q_{e}\right)$ to obtain $Q_{\text {sleak }}$. Both $Q_{\text {del }}$ and $Q_{e}$ are usually relatively large compared 
with the duct leakage rates, and so $\mathrm{Q}_{\text {sleak }}$ is calculated as the difference between two numbers of similar size, which is a classic recipe for large percentage error in the result.

Despite this, we'll not reject the outside-air method out of hand. It might happen that it could yield uncertainties that, while larger than those of the inside-air method, are still acceptable. In that case, the convenience of not having to link the air handler to the conditioned space might outweigh the larger errors which, on average, the outside-air method would entail.

\section{ACCURACY DEPENDS ON ENVELOPE TIGHTNESS}

Before beginning the analysis, it is important to point out one major factor in the overall evaluation of the nulling test. Despite the fact that the envelope leakage flow coefficient does not figure in the calculations of duct leakage rates, the accuracy of the test does depend on envelope tightness.

It is true that the nulling test does not change the neutral level (the vertical height at which the inside-to-outside pressure difference is zero). It is also true that the nulling test renders moot certain mathematical assumptions that are needed in the house pressure test.

Nevertheless, the leakier the house envelope, the less accurate the nulling test will be. That this is so can be seen by visualizing the nulling process not as an attempt to match exactly the target house pressure (an impossibility) but rather to bring the house pressure within a given tolerance of the target. One then recognizes that, for a leaky envelope, the range of air flow rates through the fan/flowmeter that will bring the house pressure within such a tolerance limit will be greater than the corresponding range if the envelope is tight. The limiting case is if the envelope has a very large hole (such as all the doors and windows open). In that case, the house pressure will be zero regardless of what is done with the system fan and the fan/flowmeter, and the measured duct leakage rates will have extremely large error bars.

\section{FIRST PART OF NULLING TEST: MEASUREMENT OF UNBALANCED LEAKAGE}

In the first part of the nulling test, which measures the unbalanced leakage, the house pressure is initially measured with the system fan off. This provides the "null pressure" that is to be matched, after the system fan is turned on, by adjusting the blower-door air-flow until the house pressure reverts back to the null pressure. This assures that the envelope pressure distribution is the same as it was before. ${ }^{1}$ Since the net leakage into the envelope $Q_{\text {env }}$ must be zero under those

${ }^{1}$ Strictly speaking, the ducts should be isolated from the conditioned space during the initial pressure measurement, since otherwise leakage area in the ducts themselves will bias the result. Francisco and Palmiter (1999) pointed out this potential for bias but did not adjust for it experimentally, presumably in the belief that the amount of bias would not be important. That may well be the case in most instances. If it turns out to be a problem, blocking the registers during the initial test should solve it. 
conditions (as much air leaking in as out), it must still be zero after the pressures are matched. Therefore, the blower-door air flow ${ }^{2}$ is equal to the difference between the supply and return duct leakage rates. This is equivalent to the statement that:

$$
Q_{\text {sleak }+ \text { rleak }}=Q_{b d}
$$

This would be strictly true if it were possible to match precisely the house pressure with the system fan on to that with the system fan off. There will, however, always be an uncertainty in the goodness of the match, and this will contribute to the uncertainty in $\mathrm{Q}_{\text {sleak+rleak. }}$. One cannot assume that $\mathrm{Q}_{\text {env }}$ is exactly zero. Therefore, it is necessary to add this term to Equation 1 if a useful error analysis is to be performed:

$$
Q_{\text {sleak+rleak }}=Q_{b d}+Q_{e n v}
$$

Although it will usually be true that $\left|Q_{\text {env }}\right|<<\left|Q_{b d}\right|$ because insuring this condition is the whole objective of the nulling procedure, this does not necessarily mean that the variations in these terms under the influence of measurement errors will have the same relationship. In fact, it is quite possible for the uncertainty in $Q_{e n v}$ to exceed the uncertainty in $Q_{b d}$, sometimes by a wide margin.

Random errors in the measured blower-door flow rate will stem mainly from errors in measuring the fan-throat pressure from which the flow rate is derived. There is also the possibility of calibration error, which will be systematic for a given piece of test equipment but random if an ensemble of blower doors is being considered.

Deviations of $Q_{\text {env }}$ from zero will stem mainly from two sources: errors in measuring the house pressure when the fan is off, and errors in matching the fan-on house pressure to this target value. We will assume that errors in $\mathrm{Q}_{\mathrm{bd}}$ and $\mathrm{Q}_{\mathrm{env}}$ are independent of each other (uncorrelated). If that is true we may write:

$$
\operatorname{err} Q_{\text {sleak }+ \text { rleak }}=\sqrt{\operatorname{err} Q_{b d}^{2}+\operatorname{err} Q_{e n v}^{2}}
$$

where "err" in front of any quantity denotes an uncertainty in that quantity. The confidence level of the uncertainty is left unspecified except for the proviso that this must be the same for all uncertainties in any equation. That is, if errQ $_{\text {sleak }+ \text { rleak }}$ is to be at a $95 \%$ confidence level in Equation 3, than $\mathrm{errQ}_{\mathrm{bd}}$ and errQ $\mathrm{env}_{\text {en }}$ must each be expressed to $95 \%$ confidence.

${ }^{2}$ Remember we are calling the first fan/flowmeter (the one in the envelope) the blower door even though a duct blower might be used instead. Similarly, we are calling the second fan/flowmeter (which blows air into the air handler in the second part of the test) the duct blower even though a blower door may in some cases be used. 
No theory is offered to aid in estimating errQ ${ }_{b d}$. Instead, it is treated as a fundamental parameter to be estimated on the basis of manufacturers" specifications and field experience. For further discussion see the section "Benchmarking the Uncertainties," below.

Errors in $\mathrm{Q}_{\mathrm{env}}$ can be investigated further, by writing the equation linking pressure to flow:

$$
Q_{e n v}=-C_{e n v} \operatorname{sign}\left(P-P_{0}\right)\left|P-P_{0}\right|^{n_{e n v}}
$$

where $\operatorname{sign}\left(P-P_{0}\right)$ is inserted to insure that $Q_{\text {env }}$ will have the sign opposite to that of the controlling pressure. Note that $\mathrm{P}-\mathrm{P}_{0}$ is used rather than just $\mathrm{P}$ to account for the fact that pressures are usually measured somewhere other than the neutral level, and it is the difference between the fan-on and fan-off pressures that we are trying to "null out."

$Q_{\text {env }}$ can now be seen to depend on three variables: $P, P_{0}$, and $C_{e n v}{ }^{3}$ The differential of $Q_{e n v}$ can then be written:

$$
d Q_{e n v}=\frac{\partial Q_{e n v}}{\partial P} d P+\frac{\partial Q_{e n v}}{\partial P_{0}} d P_{0}+\frac{\partial Q_{e n v}}{\partial C_{e n v}} d C_{e n v}
$$

For uncorrelated errors, one can now identify the squares of $\mathrm{dQ}_{\mathrm{env}}, \mathrm{dP}, \mathrm{dP}_{0}$, and $\mathrm{dC}_{\text {env }}$ with $\left(\mathrm{errQ}_{\mathrm{env}}\right)^{2},(\mathrm{errP})^{2},\left(\mathrm{err} \mathrm{P}_{0}\right)^{2}$, and $\left(\mathrm{errC}_{\mathrm{env}}\right)^{2}$, respectively, with cross terms equaling zero, to give:

$$
e r r Q_{e n v}=\sqrt{\left(\frac{\partial Q_{e n v}}{\partial P}\right)^{2}(e r r P)^{2}+\left(\frac{\partial Q_{e n v}}{\partial P_{0}}\right)^{2}\left(e r r P_{0}\right)^{2}+\left(\frac{\partial Q_{e n v}}{\partial C_{e n v}}\right)^{2}\left(e r r C_{e n v}\right)^{2}}
$$

where the partial derivatives are given by:

$$
\begin{aligned}
& \frac{\partial Q_{e n v}}{\partial P}=-n_{e n v} C_{e n v}\left|P-P_{0}\right|^{n_{e n v}-1} \\
& \frac{\partial Q_{e n v}}{\partial P_{0}}=n_{e n v} C_{e n v}\left|P-P_{0}\right|^{n_{e n v}-1} \\
& \frac{\partial Q_{e n v}}{\partial C_{e n v}}=-\operatorname{sign}\left(P-P_{0}\right)\left|P-P_{0}\right|^{n_{e n v}}=\frac{Q_{e n v}}{C_{e n v}}
\end{aligned}
$$

${ }^{3}$ The uncertainty in the envelope leakage has been treated as an uncertainty in $\mathrm{C}_{\mathrm{env}}$, with $n_{\text {env }}$ fixed, rather than an interdependent mix of errors in $\mathbb{C}_{\text {env }}$ and $n_{\text {env }}$. Given that, as seen below, the result will not depend on the uncertainty in $\mathrm{C}_{\mathrm{env}}$, this should be an acceptable approximation. 
Examining Equation $7 \mathrm{c}$, it is inviting to set $\partial \mathrm{Q}_{\text {env }} / \partial \mathrm{C}_{\mathrm{env}}$ equal to zero since the target value of $\mathrm{Q}_{\mathrm{env}}$ is zero. This is, in fact, what we propose to do. ${ }^{4}$

It would also seem reasonable to assume that the uncertainty in measuring the null pressure (errP $\mathrm{P}_{0}$ ) is essentially the same as the uncertainty in matching it (errP). Under these assumptions, Equation 6 simplifies to:

$$
\operatorname{err} Q_{e n v}=\sqrt{2} n_{e n v} C_{e n v}\left|P-P_{0}\right|^{n_{e n v}-1} \operatorname{err} P
$$

This equation is fairly simple, but it nevertheless poses a problem. What happens when $P=P_{0}$ ? Since $\mathrm{n}_{\mathrm{env}}<1$, Equation 8 implies that the uncertainty in $\mathrm{Q}_{\mathrm{env}}$ is infinite in that case. Is this credible?

No. What is happening is that for $P$ in the neighborhood of $P_{0}$ the graph of $Q_{e n v}$ becomes very nearly vertical, but it is only truly vertical at a single point. So uncertainty in $\mathrm{Q}_{\mathrm{env}}$ remains finite even if the measured values of $\mathrm{P}$ and $\mathrm{P}_{0}$ are exactly the same. It simply becomes necessary to replace the derivative $\partial \mathrm{Q}_{\mathrm{env}} /\left.\partial \mathrm{P}\right|_{\mathrm{P}=\mathrm{Po}}$ (which is undefined) by the finite difference $\Delta \mathrm{Q}_{\mathrm{env}} / \Delta \mathrm{P}$, and then let $\Delta \mathrm{P}=\mathrm{errP}$. From Equation 4 we may write:

$$
\left|\frac{\Delta Q_{e n v}}{\Delta P}\right|=\frac{C_{e n v} \Delta P^{n_{e n v}}}{\Delta P}=C_{e n v} \Delta P^{n_{e n v}-1}
$$

This is the slope of a straight line drawn from the origin $(0,0)$ to the point $\left(\Delta \mathrm{P}, \Delta \mathrm{Q}_{\mathrm{env}}\right)$.

Substituting this in place of the derivative in Equation 6 and letting $\Delta \mathrm{P}=\operatorname{err} \mathrm{P}$ results in the following equation:

$$
\left(\operatorname{err} Q_{e n v}\right)_{\max }=\sqrt{2} C_{e n v}(\operatorname{err} P)^{n_{e n v}}
$$

where the subscript max has been added to indicate that this is the largest plausible value for the uncertainty in $\mathrm{Q}_{\mathrm{env}}$.

${ }^{4}$ From Equation 4 , the ratio of $\left(\mathrm{Q}_{\text {env }} / \mathrm{C}_{\text {env }}\right)$ errC $\mathrm{C}_{\text {env }}$ to $\left(\mathrm{n}_{\mathrm{env}} \mathrm{C}_{\mathrm{env}}\left|\mathrm{P}-\mathrm{P}_{\mathrm{o}}\right|^{\text {nenv }-1}\right)$ errP is $\left(\left|\mathrm{P}-\mathrm{P}_{0}\right| / \mathrm{errP}\right)\left(\mathrm{errC}_{\text {env }} / \mathrm{C}_{\text {env }}\right)$. Since the whole point of the nulling test is to insure that $\left|\mathrm{P}-\mathrm{P}_{0}\right|$ will be as close to zero as possible, it is reasonable to suppose that $\left|\mathrm{P}-\mathrm{P}_{0}\right|$ will be comparable in magnitude to errP (perhaps within a factor $\sqrt{ } 2$ ). The first factor in the ratio will therefore be on the order of unity, i.e., within about a factor of two of 1.0. Second, since a measurement of $\mathrm{C}_{\text {env }}$ will be done with a view to reasonable accuracy (within 10\% certainly, and probably better than that) then the whole ratio will be on the order of 0.1 . Since the two quantities in the ratio will be added in quadrature, ignoring the smaller of the two will introduce a negligible error in the result. 
If errP $>\left|P-P_{0}\right|$, then err $Q_{\text {env }}$ (calculated using Equation 8) is less than (errQ $\mathrm{env}_{\text {enax }}$ (calculated using Equation 10). The two expressions are equal for $\operatorname{err} P=\left|\mathrm{P}-\mathrm{P}_{0}\right|$. For $\left|\mathrm{P}-\mathrm{P}_{0}\right|<\operatorname{err} \mathrm{P}$, the value of err $Q_{\mathrm{env}}$ becomes greater than that of $\left(\mathrm{errQ}_{\mathrm{env}}\right)_{\max }$, heading on up toward infinity as $\mid \mathbf{P}$ $\mathrm{P}_{0} \mid$ approaches zero.

In light of the above considerations, values of errQ $Q_{\text {env }}$ greater than (errQ $\left.\mathrm{Q}_{\mathrm{env}}\right)_{\max }$ will be rejected, and

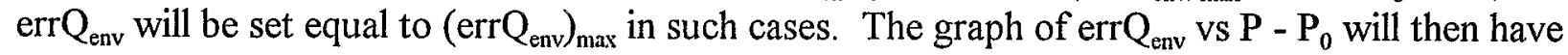
a flat "mesa top" of height (errQ $\left.\mathrm{Q}_{\mathrm{env}}\right)_{\max }$ running from $\mathrm{P}-\mathrm{P}_{0}=0$ to $\mathrm{P}-\mathrm{P}_{0}=\operatorname{errP}$.

We would also like to reject values of $\left|\mathrm{P}-\mathrm{P}_{0}\right|$ considerably in excess of errP, since errP is just an estimate of the uncertainty in either $\mathrm{P}$ or $\mathrm{P}_{0}$. Before doing so, however, one needs to consider what "considerably" means, because $\left|\mathrm{P}-\mathrm{P}_{0}\right|$ will often be somewhat in excess of errP. Indeed, according to the above reasoning, the expected value of $\left|\mathrm{P}-\mathrm{P}_{0}\right|$ is $1.13 \mathrm{errP}$ if errP is a one standard deviation uncertainty. ${ }^{5}$ Not only is this greater than errP, but it implies that, sometimes, $\left|\mathrm{P}-\mathrm{P}_{0}\right|$ will be greater still.

To investigate this question, one can parameterize $\left|\mathrm{P}-\mathrm{P}_{0}\right|$ as $\mathrm{k}$ errP, where $\mathrm{k}$ is a coefficient that will have values, usually, in the range $0<\mathrm{k}<3$. If this is done, then Equation 8 becomes:

$$
e r r Q_{e n v}=\sqrt{2} k^{n_{e n v}-1} C_{e n v}(e r r P)^{n_{e n v}}
$$

This equation looks very much like Equation 10 , except for the factor $\mathrm{k}^{\text {nenv-1 }}$. Table 1 shows values of the coefficient in Equation 11 (including the $\sqrt{ } 2$ factor) for various values of $\mathrm{k}$, using $\mathrm{n}_{\mathrm{env}}$ $=0.65$. (If $\mathrm{n}_{\text {env }}$ is varied to 0.55 or 0.75 , the coefficient varies by $0 \%$ for $\mathrm{k}=1,7 \%$ for $\mathrm{k}=2$, and $11 \%$ for $\mathrm{k}=3$.)

Table 1. Values of the coefficient in Equation 11 for $n_{\text {env }}=0.65$.

\begin{tabular}{|l|l|}
\hline $\mathrm{k}\left[=\left|\mathrm{P}-\mathrm{P}_{0}\right| / \mathrm{errP}\right]$ & $\sqrt{ } 2 \mathrm{k}^{\text {nenv-1 }}\left[=\mathrm{err}_{\mathrm{env}} /\left(\mathrm{C}_{\mathrm{env}}(\mathrm{errP})^{\text {nenv }}\right)\right]$ \\
\hline$<1$ & 1.41 (maximum value using Equation 10$)$ \\
\hline 1 & 1.41 \\
\hline 1.5 & 1.23 \\
\hline 2 & 1.11 \\
\hline 3 & 0.96 \\
\hline
\end{tabular}

${ }^{5}$ The 1.13 errP is the product of of a one standard deviation uncertainty in $\left|\mathrm{P}-\mathrm{P}_{0}\right|$, which is $\sqrt{ } 2 \mathrm{errP}$, and the expected value of the right half of a normal distribution $(0<z<\infty)$ as a fraction of its standard deviation, which is 0.798 . 
In light of this table, let us choose 1.23 as a representative value of this coefficient, expecting seldom to be off by more than $15 \%$. A $15 \%$ error in the estimate of an error should be acceptable. Therefore, in everything that follows we will use:

$$
\operatorname{err} Q_{e n v}=1.23 C_{e n v}(e r r P)^{n_{e n v}}
$$

This was a long path to a simple estimator for the uncertainty in the envelope leakage, but now we can insert this into Equation 3 to obtain an expression for the uncertainty in the unbalanced leakage:

$$
e r r Q_{\text {sleak }+ \text { rleak }}=\sqrt{\left(\operatorname{err} Q_{b d}\right)^{2}+1.5 C_{e n v}^{2}(e r r P)^{2 n_{e n v}}}
$$

where 1.5 is used for the square of 1.23 , appropriate within the degree of approximation adopted.

Some houses do not have return ductwork, but instead have the equipment located within the conditioned space and a return grille that cannot communicate in any way with the outside. In such cases, $\mathrm{Q}_{\text {reak }}$ equals zero, $\mathrm{Q}_{\text {sleak }}=\mathrm{Q}_{\text {sleak+rleak }}$, and we are finished. The second part of the nulling test is not needed. Caution is in order, however, in using this assumption. Sometimes it will appear that a return is entirely within the conditioned space, yet it nevertheless has airflow paths to or from the outside. A "platform return" located with one side adjacent to an exterior wall and the bottom over a crawl space is a common example of such a return. Such returns should be treated as full duct systems. 


\section{SECOND PART OF THE NULLING TEST: MEASURING THE SUPPLY LEAKAGE}

In the second part of the nulling test, the supply leakage is measured as a separate quantity. The procedure has been discussed above, in the section "Description of the Nulling Test." There, the two methods of performing the second part of the test-the inside-air method and the outside-air method-were described. The analysis of measurement uncertainties in each of the two methods is presented here.

\section{$\underline{\text { Inside-Air Method }}$}

Let us first consider the inside-air method. In the same manner as in the unbalanced leakage part of the test, it can be argued that the supply leakage is equal to the measured flow through the blower door plus the net envelope leakage, where we do our best to insure that the latter quantity is as close as possible to zero. So for the purposes of calculating the supply leakage, we use an analogue of Equation 1:

$$
Q_{\text {sleak }}=Q_{b d, s}
$$

where the " $\mathrm{s}$ " in the second subscript distinguishes this blower-door air flow from the one measured earlier during the unbalanced-leakage test. For the error analysis, however, it is again necessary to include $Q_{\text {env }}$ in the equation, and write an expression analogous to Equation 2:

$$
Q_{\text {sleak }}=Q_{b d, s}+Q_{e n p, s}
$$

Using the identical reasoning to that employed in the analysis of the unbalanced leakage test, one arrives at the expression

$$
e r r Q_{\text {sleak }}=\sqrt{\left(\operatorname{err} Q_{b d, s}\right)^{2}+\left(\operatorname{err} Q_{e n, s}\right)^{2}}
$$

From this point all the same mathematics goes through, leading to

$$
\operatorname{err} Q_{\text {sleak }}=\sqrt{\left(e r r Q_{b d, s}\right)^{2}+1.5 C_{e m}^{2}(\operatorname{err} P)^{2 n_{c n v}}}
$$

in which it is assumed that the uncertainty in the pressure measurements is the same in this part of the test as it was before.

The calculation of return leakage and its uncertainty can now be done:

$$
Q_{\text {rleak }}=Q_{\text {sleak }}-Q_{\text {sleak }+ \text { rleak }}
$$


If all errors are uncorrelated, the uncertainty in $\mathrm{Q}_{\text {rleak }}$ is given by:

$$
\begin{aligned}
\operatorname{err} Q_{\text {rleak }} & =\sqrt{\left(\operatorname{err} Q_{\text {sleak }}\right)^{2}+\left(\operatorname{err} Q_{\text {sleak }+ \text { rleak }}\right)^{2}} \\
& =\sqrt{\left(\operatorname{err} Q_{b d}\right)^{2}+\left(\operatorname{err} Q_{b d, s}\right)^{2}+3 C_{e n v}^{2}(e r r P)^{2 n_{e n v}}}
\end{aligned}
$$

Equation 19 is likely to overestimate somewhat the contribution of the blower-door measurements, because the errors in the two measurements are likely to be significantly correlated, and $\mathrm{Q}_{\text {rleak }}$ is found by subtracting them. A lower limit on err $\mathrm{Q}_{\text {rleak }}$ can be found by assuming that the deviations of $\mathrm{Q}_{\mathrm{bd}}$ and $\mathrm{Q}_{\mathrm{bd}, \mathrm{s}}$ from their "true" values are maximally correlated and equal. In that case, their errors cancel and Equation 19 reduces to:

$$
\left(\operatorname{err} Q_{\text {rleak }}\right)_{\min }=1.7 C_{e n v}(e r r P)^{n_{e n v}}
$$

\section{Outside-Air Method}

In the outside-air method, the provision of an air path from the living space to the duct blower is omitted. This will usually save time and effort, but it comes at the cost of adding uncertainty in the results. For one thing, there is an extra term in the uncertainty expression. For another, one of the existing terms becomes much larger. These things happen because the blower door now measures, not the supply leakage directly, but the rate of air delivery to the house by the duct system. The supply leakage must be calculated by subtracting this measured flow rate from the air flow rate at the system fan:

$$
Q_{\text {sleak }}=Q_{e}-Q_{b d, s}
$$

for the purposes of calculation, and

$$
Q_{\text {sleak }}=Q_{e}+Q_{e n v}-Q_{b d, s}
$$

for the purposes of uncertainty analysis.

This leads to the following expression for the uncertainty in the supply leakage:

$$
e r r Q_{s l e a k}=\sqrt{\left(e r r Q_{e}\right)^{2}+\left(e r r Q_{b d, s}\right)^{2}+1.5 C_{e n v}^{2}(e r r P)^{2 n_{e n v}}}
$$

Not only is there a term in Equation 23 that was absent in Equation 17, but the uncertainty in the blower-door air flow rate $\left(\mathrm{errQ}_{\mathrm{bd}, \mathrm{s}}\right)$ will usually be much larger in Equation 23 than in Equation 17 because the size of the flow to be measured is larger. For example, suppose the system fan flow rate is $1200 \mathrm{cfm}$ and the supply leakage rate is $200 \mathrm{cfm}$. Then $\mathrm{Q}_{\mathrm{bd}, \mathrm{s}}$ will be $\sim 200 \mathrm{cfm}$ in Equation 17 but $1000 \mathrm{cfm}$ in Equation 22. (Generally, the larger a flow rate, the larger will be the uncertainty in its measured value.) 
In the outside-air method, the return leakage is calculated the same way as in the inside-air method, using Equation 18:

$$
Q_{\text {rleak }}=Q_{\text {sleak }}-Q_{\text {sleak }+ \text { rleak }} \quad(18 \text { repeated })
$$

from which the uncertainty in the return leakage works out to:

$$
\begin{aligned}
\operatorname{err} Q_{\text {rleak }} & =\sqrt{\left(e r r Q_{e}\right)^{2}+\left(\operatorname{err} Q_{\text {sleak }}\right)^{2}+\left(\operatorname{err} Q_{\text {sleak }+ \text { rleak }}\right)^{2}} \\
& =\sqrt{\left(\operatorname{err} Q_{e}\right)^{2}+\left(\operatorname{err} Q_{b d}\right)^{2}+\left(e r r Q_{b d, s}\right)^{2}+3.2 C_{e n v}^{2}(\operatorname{err} P)^{2 n_{e n v}}}
\end{aligned}
$$

In the outside-air method, errQ $\mathrm{Q}_{\mathrm{bd}, \mathrm{s}}>>\operatorname{err}_{\mathrm{bd}}$, so Equation 24 can be simplified to:

$$
\operatorname{err} Q_{\text {rleak }}=\sqrt{\left(e r r Q_{e}\right)^{2}+\left(e r r Q_{b d, s}\right)^{2}+3 C_{e n v}^{2}(e r r P)^{2 n_{e n v}}}
$$

The gross inequality of err $\mathrm{Q}_{b d}$ and errQ $\mathrm{Q}_{b \mathrm{~d}, \mathrm{~s}}$ renders moot any concern about correlation of these two uncertainties.

\section{BENCHMARKING THE UNCERTAINTIES}

At this point, we have obtained expressions for the uncertainties in the supply and return leakage rates as measured using both versions of the nulling test. It remains to put typical numbers on these uncertainties, and to see whether some of the terms in Equations 17, 19, 22, and 23 are always or usually more significant than others. Should that be the case, some simplification of these equations may be achieved.

The quantities appearing in these equations can be listed:

$$
\mathrm{C}_{\mathrm{env}} \quad \mathrm{n}_{\mathrm{env}} \quad \operatorname{errP} \quad \operatorname{err}_{\mathrm{bd}} \quad \operatorname{err}_{\mathrm{bd}, \mathrm{s}} \quad \operatorname{err}_{\mathrm{e}}
$$

The first two specify the leakage characteristics of the envelope, and the other four are uncertainties in the measured quantities. Let us look at each of these in turn.

Envelope leakage rates in American housing vary widely, but in terms of CFM50 most will fall in the range 500 to 5000 . The measured exponents also vary, but usually fall in the range 0.55 to 0.75 . For the purposes of this benchmarking exercise, we'll set nenv $=0.65$, a conventional choice, and run several values of $\mathrm{C}_{\text {env }}: 50,100,200,300$, and $400 \mathrm{cfm} / \mathrm{Pa}^{65}$. 
The other quantities are all measurement uncertainties, and an uncertainty is meaningless unless it is accompanied by a confidence level. Unfortunately, in the benchmarking process below, it is not possible to be as precise as one would like about this, because the data necessary to do this are not always available. Particularly with regard to a manufacturer's specification of accuracy, it is difficult to know what level of confidence to assign to this. So it is necessary to make some assumptions, but at least these should be stated as clearly as possible:

1. Estimates of statistical uncertainties will be made as one standard deviation in a normally distributed set of measurements.

2. Where a manufacturer's estimate of accuracy is used, it will be assumed that the units are uniformly distributed within the specified limits. One standard deviation will then span $\sim 60 \%$ of the specified range. this is equivalent to assuming a normal distribution in which $92 \%$ of the units meet the manufacturer's specification.

Let us start with a consideration of pressure measurements. These are usually made with a digital gauge that reads to tenths of a pascal. It is possible to reduce random uncertainty in a measurement by repeating it many times, so that the standard deviation of the mean decreases as the square root of the number of measurements. Theoretically, there is no lower limit to this uncertainty. Nevertheless, systematic error in instrument calibration and variations in pressures, caused by wind shifts and gusts, will put a practical floor on achievable accuracy. The digital gauges generally used in the field read to tenths of a pascal, so it seems reasonable to claim that $0.1 \mathrm{~Pa}$ is the lower limit of plausible uncertainties in $\mathrm{P}$. One such meter is quoted as having an accuracy of $\pm 1 \%$, or 2 counts, whichever is greater. This would seem to imply a minimum uncertainty of $0.2 \mathrm{~Pa}$. However, since the nulling test only requires that one pressure be matched to another, a systematic error in the house pressure readings will not matter. So from this standpoint a $0.1 \mathrm{~Pa}$ lower limit for errP is still a possibility.

Practical experience, however, indicates that reducing the random uncertainty in the house pressure to $0.1 \mathrm{~Pa}$ will require many measurements. Even reducing this to $0.2 \mathrm{~Pa}$ may be difficult in anything but calm wind conditions. We will proceed with the benchmarking analysis using 0.1 , 0.2 , and $0.3 \mathrm{~Pa}$ as candidate values for the uncertainty in house pressure.

The uncertainties in air-flow measurements (errQ $\mathrm{bd}_{\mathrm{b}}$ and $\operatorname{err}_{\mathrm{bd}, \mathrm{s}}$ ) may depend on the equipment used. For low flow rates one will do well to employ a duct blower rather than a blower door, since the lower limit of flow rates that can be measured with a typical blower door is $\sim 100 \mathrm{cfm}$ if the smallest ring is used, whereas a typical duct blower can measure flows as small as $20 \mathrm{cfm}$.

A manufacturer of test equipment claims 5\% accuracy for a blower door and $3 \%$ for a duct blower, within the range of calibration. This includes instrument error only; additional uncertainty may be expected because of operator error, which may have both systematic and random 
components. The random component may in some cases be reduced to the $1 \%-2 \%$ range. ${ }^{6}$ A uniform distribution with a $\pm 5 \%$ range will be used as a benchmark, which implies a one standard deviation error bar of $3 \%$.

If this is agreed upon, then for the inside-air method, the blower door will be measuring flow rates comparable to duct leakage rates, i.e., usually in the range $0-300 \mathrm{cfm}$. The range of measurement errors then will be $0-9 \mathrm{cfm}$. For benchmarking purposes, we'll take $10 \mathrm{cfm}$ as a conservative estimate. For the outside-air method (in the second part of the test), the flow rate to be measured will be larger, because it is now the delivered air flow rate rather than the duct leakage rate. This may be benchmarked as typically a $1200 \mathrm{cfm}$ system fan flow rate minus a typical $200 \mathrm{cfm}$ leakage rate, or $\sim 1000 \mathrm{cfm}$. A $3 \%$ error will then be $\sim 30 \mathrm{cfm}$.

System fan flow can be measured in several ways. ASHRAE Standard 152P prescribes a method using a duct blower applied to a system with blocked return, very similar to what is used in the second part of the nulling test. In one "round robin" test of the fan flow measurement procedure (Andrews et al. 1998) the standard deviation of fan flow measurements was $3.6 \%$ of the mean of five measurements. Allowing that an experienced operator might be able to reduce this uncertainty somewhat, we will benchmark a $3 \%$ uncertainty in the fan flow rate. Three percent of a typical $1200 \mathrm{cfm}$ flow rate is $36 \mathrm{cfm}$.

The quantities appearing under a radical in Equations 17, 19, 23, and 25 are:

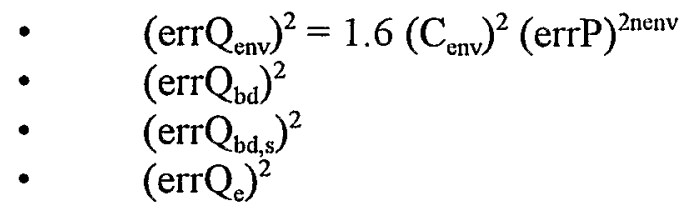

All but the first of these have been benchmarked above. To summarize, we are using:

- $\quad$ errQ $_{\mathrm{bd}}=10 \mathrm{cfm}$, so $\left(\mathrm{errQ}_{\mathrm{bd}}\right)^{2}=100 \mathrm{cfm}^{2}$.

- $\quad$ errQ $\mathrm{bd}, \mathrm{s}=10 \mathrm{cfm}$ for the inside-air method, so $\left(\mathrm{errQ}_{\mathrm{bd}, \mathrm{s}}\right)^{2}=100 \mathrm{cfm}^{2}$ if inside air is used. .

$=50 \mathrm{cfm}$ for the outside-air method, so $\left(\mathrm{errQ}_{\mathrm{bd}, \mathrm{s}}\right)^{2}=2500 \mathrm{cfm}^{2}$ in this case.

- $\quad \mathrm{errQ}_{\mathrm{e}}=60 \mathrm{cfm}$ (relevant to outside-air method only), so $\left(\mathrm{errQ}_{\mathrm{e}}\right)^{2}=3600 \mathrm{cfm}^{2}$.

The quantity $1.5\left(\mathrm{C}_{\mathrm{env}}\right)^{2}$ (errP $)^{2 \mathrm{nenv}}$ is composed of two parameters for which it was found necessary to consider ranges of values as opposed to a single benchmark. Therefore, a matrix of values for this quantity will be needed. Table 2 shows values of $1.5\left(\mathrm{C}_{\text {env }}\right)^{2}(\mathrm{errP})^{2 \text { nenv }}$ for the benchmark values of errP and $\mathrm{C}_{\text {env }}$.

${ }^{6}$ In a study relating to another duct leakage test (Andrews 2000) the average deviation of blower-door measurements from the theoretical curve was found to be in the $1 \%$ to $2 \%$ range. 
Table 2. Values of $1.5\left(\mathrm{C}_{\text {env }}\right)^{2}(\mathrm{errP})^{2 \text { nenv }}$ for benchmark values of envelope leakage and measurement uncertainty of pressures.

\begin{tabular}{|l|c|c|c|}
\hline \multicolumn{1}{|c|}{$\begin{array}{c}\text { errP, Pa } \\
\mathrm{C}_{\text {env, }} \mathrm{cfm} / \mathrm{Pa}^{0.65}\end{array}$} & 0.1 & 0.2 & 0.3 \\
\hline 50 & 190 & 460 & 780 \\
\hline 100 & 750 & 1850 & 3140 \\
\hline 200 & 3010 & 7400 & 12600 \\
\hline 300 & 6770 & 16700 & 28200 \\
\hline 400 & 12000 & 30000 & 50200 \\
\hline
\end{tabular}

Note: the Cenv values correspond to CFM50 values ranging from 640 to 5000 .

All of these values are higher, and in most cases considerably higher, than the $100 \mathrm{cfm}^{2}$ benchmarked for $\left(\mathrm{errQ}_{\mathrm{bd}}\right)^{2}$. This doesn't mean it isn't important to measure the flow rates accurately. Achieving $10 \mathrm{cfm}$ accuracy could prove problematic in some cases. It just means that reducing the uncertainty below this level usually will not buy much additional accuracy.

\section{Inside-Air Method}

Tables 3 and 4 show the expected uncertainties in the measured supply and return leakage rates for the inside-air method, for the values of $\mathrm{C}_{\text {env }}$ and errP considered in Table 2. Some cells of Table 4 display two values, the smaller one assuming correlated $\mathrm{Q}_{\mathrm{bd}}$ and $\mathrm{Q}_{\mathrm{bd}, \mathrm{s}}$ and the larger one assuming that these are uncorrelated.

The point of showing these thickets of numbers is to illustrate the strong dependence of the uncertainty on the envelope leakage flow coefficient and the pressure measurement uncertainty. It should also be noted that, except for the upper left corner of Tables 3 and 4, where the envelope is tight and the pressure measurement uncertainty is low, the dependence on air-flow measurement uncertainty is relatively weak. It may be useful to put numbers on this statement. Even if the air-flow measurement were assumed to be perfectly accurate, the uncertainties in the measured leakage rates would not decrease by more than $3 \mathrm{cfm}$ on the supply side or $4 \mathrm{cfm}$ on the return side.

\section{Outside-Air Method}

As stated above, the outside-air method is often easier than the inside-air method, since there is no need for an air flow path from the conditioned space to the duct blower. Unfortunately, the measurement uncertainties are increased, particularly in those cases where the inside-air method 
works best. This is shown in Tables 5 and 6 . The difference between the outside-air and insideair methods, from the standpoint of uncertainties in the duct leakage rates, is that using outside air puts a floor under these uncertainties commensurate with the errors expected from the measurements of system fan flow and the delivered air flow. With outside air, the uncertainties in the nulling test will be relatively large even in tight houses and even if the pressure measurements can be done very accurately. The outside-air method compares well with the inside-air method only in those cases where the accuracy of both methods is poorest.

For these reasons it is probably safe to relegate the outside-air method to a secondary level of consideration, at least until a breakthrough can be made in the design of the test, to eliminate the problem of a large percentage error arising from the use of a difference of two quantities of similar size.

\section{COMPARISON WITH EXPERIMENTAL DATA}

Preliminary field test data on the nulling test are available from two sources. Francisco and Palmiter (1999) performed 12 nulling tests. In each of these houses, they had a method for making a "best estimate" of the actual duct leakage that is likely to be more accurate than any of the individual duct leakage test methods they tried. The envelope leakage flow coefficients in the houses where the nulling test was tried ranged from 126 to $166 \mathrm{cfm} / \mathrm{Pa}{ }^{\text {nenv }}$, with an average value of 150. (The measured exponents ranged from 0.63 to 0.70 .) The deviations of the leakage flows as measured with the nulling test from the "best estimate" values are shown in Table 7. The standard deviations were based on an assumed population mean deviation of zero, and were calculated as best estimates of population standard deviations, i.e., using $(\mathrm{n}-1)$ in the denominator.

The supply-leakage data are consistent with a 0.1-Pa pressure measurement uncertainty (Table 5). Strikingly absent, though, is the expected greater uncertainty on the return side as compared with the supply side. Note is taken in passing of the fact that in six of the 12 cases, the deviations from "best estimate" on the supply and return sides were exactly the same. One would not expect this a priori, but for whatever reason it occurred, it would reduce any average difference between the deviations on the supply and return sides.

If the benchmarking analysis is even approximately correct, correlation of blower-door errors should not affect the results from these houses significantly. If that is true, correlation is probably not an explanation for the lack of difference in the supply- and return-side deviations. This possibility has to be held open, however, pending acquisition of additional data. 
Table 3. Uncertainties in supply leakage (err $\mathrm{Q}_{\text {sleak }}$ ) for the inside-air method, using Equation 17 for selected values of envelope leakage and measurement uncertainty of pressures and air-flows.

errQ $\mathrm{Q}_{\text {sleak }}, \mathrm{cfm}$, inside-air method

\begin{tabular}{|l|l|l|l|}
\hline \multicolumn{1}{|c|}{$\begin{array}{c}\text { errP, Pa } \\
\mathrm{C}_{\text {env, }} \mathrm{cfm} / \mathrm{Pa}^{0.65}\end{array}$} & \multicolumn{1}{|c|}{0.2} & \\
\hline 50 & 17 & 24 & 30 \\
\hline 100 & 29 & 44 & 57 \\
\hline 200 & 56 & 87 & 113 \\
\hline 300 & 83 & 130 & 168 \\
\hline 400 & 110 & 173 & 224 \\
\hline
\end{tabular}

Note: each entry equals the square root of the sum of 100 and the corresponding Table 2 entry.

Table 4. Uncertainties in return leakage (err $\mathrm{Q}_{\text {rleak }}$ ) for the inside-air method, using Equation 19 for selected values of envelope leakage and measurement uncertainty of pressures and air-flows.

err $Q_{\text {rleak }}, \mathrm{cfm}$, inside-air method

\begin{tabular}{|l|l|l|l|}
\hline \multicolumn{1}{|c|}{$\begin{array}{c}\text { errP, Pa } \\
\mathrm{C}_{\text {env, }} \mathrm{cfm} / \mathrm{Pa}^{0.65}\end{array}$} & \multicolumn{1}{|c|}{0.1} & \multicolumn{1}{c|}{0.2} & \\
\hline 50 & $19-24$ & $30-33$ & $39-42$ \\
\hline 100 & $39-41$ & $61-62$ & $79-80$ \\
\hline 200 & $78-79$ & 122 & 159 \\
\hline 300 & 117 & 183 & 237 \\
\hline 400 & 156 & 245 & 317 \\
\hline
\end{tabular}

Note: The smaller number in each cell is for correlated $\mathrm{Q}_{b d}$ and $\mathrm{Q}_{\mathrm{bd}, \mathrm{s}}$, and is equal to the square root of twice the corresponding Table 2 entry. The larger number in each cell is for uncorrelated $\mathrm{Q}_{\mathrm{bd}}$ and $\mathrm{Q}_{\mathrm{bd}, \mathrm{s}}$ and equals the square root of the sum of 200 and twice the corresponding Table 2 entry, or $\sqrt{ } 2$ times the corresponding Table 3 entry. Where there is only one number in a cell, the correlated and uncorrelated values were the same. 
Table 5. Uncertainties in supply leakage (errQ $\mathrm{Q}_{\text {sleak }}$ ) for the outside-air method, using Equation 22 for selected values of envelope leakage and measurement uncertainty of pressures and air-flows.

\begin{tabular}{|l|l|l|l|}
\multicolumn{1}{|c}{$\begin{array}{c}\text { errP, } \mathrm{Pa} \\
\mathrm{C}\end{array}$} & 0.1 & \multicolumn{1}{c|}{0.2} & 0.3 \\
$\mathrm{C}_{\text {env }} \mathrm{cfm} / \mathrm{Pa}^{0.65}$ & & & \\
\hline 50 & 49 & 52 & 55 \\
\hline 100 & 54 & 64 & 73 \\
\hline 200 & 72 & 98 & 122 \\
\hline 300 & 95 & 137 & 174 \\
\hline 400 & 119 & 179 & 229 \\
\hline
\end{tabular}

Note: each entry equals the square root of the sum of 1300 (for the system-fan flow measurement error), 900 (for the air-flow error in the second part of the test), and the corresponding Table 2 entry (for the error introduced by imperfect pressure matching).

Table 6. Uncertainties in return leakage ( $\left(\mathrm{rr}_{\mathrm{rleak}}\right)$ for the outside-air method, for selected values of envelope leakage and measurement uncertainty of pressures and air-flows.

\begin{tabular}{|l|l|l|l|}
\multicolumn{1}{|c|}{$\begin{array}{c}\text { errP, } \\
\text { erreak }\end{array}$} & \multicolumn{1}{c|}{0.1} & \multicolumn{1}{c|}{0.2} & \\
$\mathrm{C}_{\text {env }} \mathrm{cfm} / \mathrm{Pa}^{0.65}$ & & & 0.3 \\
\hline 50 & 51 & 56 & 61 \\
\hline 100 & 61 & 77 & 92 \\
\hline 200 & 91 & 130 & 166 \\
\hline 300 & 125 & 189 & 242 \\
\hline 400 & 162 & 249 & 320 \\
\hline
\end{tabular}

Note: each entry equals the square root of the sum of 1300 (for the system fan error), 900 (for the air-flow error in the second part of the test), and 2 times the corresponding Table 2 entry (for the error introduced by imperfect pressure matching). 
Table 7. Deviations of Nulling Test from "Best Estimate" from Francisco and Palmiter 1999.

\begin{tabular}{|l|l|l|l|l|l|l|l|l|l|l|l|l|l|}
\hline Duct & \multicolumn{10}{|c|}{ Individual Values } & Std. Dev. \\
\hline Supply & -23 & -6 & -35 & -34 & -55 & -52 & 69 & 17 & 0 & 8 & 31 & 82 & 44 \\
\hline Return & -23 & -56 & -35 & 1 & 13 & -48 & 69 & 0 & 0 & 9 & 31 & 82 & 43 \\
\hline
\end{tabular}

Table 8. Deviations of Nulling Test from "Best Estimate," from Cummings and Withers 1999.

\begin{tabular}{|c|c|c|c|c|c|c|c|c|c|c|c|c|}
\hline Duct & \multicolumn{5}{|c|}{ House 1 values } & Std. & \multicolumn{5}{|c|}{ House 2 values } & Std. \\
\hline Supply & -29 & -32 & 38 & 30 & 89 & 55 & -10 & -67 & -250 & -77 & -171 & 160 \\
\hline Return & -39 & -30 & -25 & -34 & -83 & 53 & -26 & -4 & -67 & -43 & -64 & 53 \\
\hline
\end{tabular}

The other published work on the nulling test was done by Cummings and Withers (1999). In this study, the nulling test was performed on five different duct leakage configurations artificially imposed on each of two houses. Their House 1 had a quite "tight" envelope, the quoted air change rate at $50 \mathrm{~Pa}$ pressure $(\mathrm{ACH} 50)$ of 4.4 translating to a $\mathrm{C}_{\text {env }}$ of $60 \mathrm{cfm} / \mathrm{Pa}{ }^{0.65}$ Their House 2 was larger and had a leakier envelope, the $\mathrm{ACH} 50$ of 7.3 translating to $\mathrm{C}_{\text {env }}=134 \mathrm{cfm} / \mathrm{Pa}^{0.65}$

The individual deviations are shown in Table 8, separated by house because of the quite different envelope leakage characteristics of the two dwellings. The House 1 data are consistent with $\sim 0.4 \mathrm{~Pa}$ pressure measurement uncertainty, though here again the expected larger deviations on the return side are not seen. In House 2, much larger deviations are observed on the supply side than on the return side, exactly the opposite of what is expected from this analysis. On average, the House 2 data are consistent with a $0.3 \mathrm{~Pa}$ measurement uncertainty, but, again, the larger errors are seen on the supply side, contrary to expectation.

It should also be noted that the mean deviation from "best estimates" is close to zero on both the supply and return sides in the Francisco and Palmiter data. In the Cummings and Withers data, the nulling test returned smaller values than the "best estimates" in 17 out of 20 cases.

Taken together, the available data indicate a need for improvement in the accuracy of the test. Even when the pressure measurement uncertainty has apparently been reduced to a practical lower limit, standard deviations of the order $40-50 \mathrm{cfm}$ are still observed. These might not be "show stoppers," but we would like to have them lower, particularly in view of the fact that the return leakage is calculated as a byproduct of the supply leakage and the unbalanced leakage, leading (theoretically at least) to potentially large errors that might show themselves in a larger data set. 


\section{CONCLUSIONS}

1. The major conclusion of this report is that, except for very tight envelopes, experimental uncertainties in the inside-air method of the nulling test will be driven by the value of the envelope leakage flow coefficient and by the uncertainty in the pressure-matching process, rather than by errors in measuring the air flow rates across the envelope.

2. The outside-air method adds two significant additional sources of error: the uncertainty in the system fan flow rate and the uncertainty in the air flow rate across the envelope during the second part of the test that measures supply leakage.

3. The calculated uncertainties are broadly consistent with those extracted from the limited field data currently available. However, the expected greater uncertainty in the return leakage (as compared with the uncertainty in the supply leakage) was not seen in the comparison of the referenced data with the researchers' "best estimate" duct leakage values. It is not known to what extent this is due to: a) statistical fluctuation; b) an artifact of the procedures used by the referenced experimenters in choosing their "best estimate" duct leakage rates for comparison; or c) some significant factor that was not captured in this analysis.

4. Except for the case of well-controlled pressure matching in very tight envelopes, the calculated uncertainties are sufficiently large to warrant a search for ways to reduce them. There is a need for further field work on the nulling test to assess the magnitude of the uncertainties, to compare these with theoretical analyses such as this one, and to determine whether the uncertainties in the nulling test can be reduced in any practical way.

\section{POSSIBLE FURTHER DEVELOPMENT OF THE NULLING TEST}

Can the nulling test be made more accurate? Although that question cannot be answered in this report, it is appropriate to offer some suggestions for how this might be done. Several of these involve combining data from the nulling test with information from other duct leakage tests, to over constrain the solution in what has elsewhere been called the "data cross-check" approach (Andrews 1998). There is reason to focus in particular on the return duct, since that side of the system is not directly measured in the nulling test.

1. One approach would be to use the same procedure that Palmiter and Francisco (1999) employed to obtain their "best estimate" leakage rates. Here it is suggested that if in the interests of economy of effort the procedure can only be done on one side of the duct system, the priority should be given to the return side, in part for the above-stated reason that the return leakage is otherwise only indirectly measured in the nulling test, but also because the return side has fewer registers and the Francisco-Palmiter "best-estimate" procedure would therefore be easier to do on that side. The percentage errors in this method will be lower if the return side is leaky than if it is tight. This method can be summarized as follows: 
A. Measure the air flow into the return register(s) with a flow hood.

B. Subtract this from the system fan flow to obtain total return leakage. (Make sure the flow hood used in A is calibrated against the duct blower used in B to minimize equipment calibration bias.)

C. Measure the total leakage flow coefficient for the return duct with a duct blower.

D. Use the above information to obtain a "best estimate" of the return-side operating pressure.

E. Measure the leakage flow coefficient between the return duct and the outside by bringing both the house and the duct to the same pressure, and combine that with the "best estimate" operating pressure to obtain the return-side leakage from outside, as described in ASHRAE 1999.

2. If one side of the system is relatively "tight," then the air leakage rate on that side can be accurately measured (as a fraction of system fan flow) using fan pressurization, even if the operating pressure in the duct is only approximately known. This will be particularly helpful if the return side is the "tight" side. This procedure could be useful in testing systems with platform returns.

3. It might also prove useful to cross-check the unbalanced leakage as obtained using the first part of the nulling test against the value for this same quantity as obtained using the house pressure test. Although the use of the house pressure test is limited in ASHRAE 1999 to a subset of all houses meeting certain criteria, the first part of this test is probably more generally applicable. The unbalanced-leakage part of the house pressure test is easy to do, and may provide a useful adjunct to the information gained from the nulling test.

4. The fourth suggestion is in a different genre from the above. It might be possible to make the pressure matching more precise by measuring the air flows over a range of house pressures that includes the target pressure. This would provide a multiplicity of pressure and air-flow values that could be plotted on a graph and used in some type of least-squares fit. Interspersed with these measurements, the house pressure with the system fan off could be measured to get a multiplicity of values for the target pressure. These multiple values of the target pressure and the air flow vs. house pressure curve could help to even out random fluctuations caused by wind. Finally, at some point in the test, a comparison of the fan-off house pressure with and without blocked registers could remove any bias from that source.

It is recognized that some of these suggestions may add significantly to the labor content of the test, and so may not be appropriate for anything but research. Nevertheless, the possibility remains that a diagnostic-type test might yet be distilled out of these ideas. Even if that proves to 
be infeasible, the availability of multiple tests from a research standpoint can be extremely valuable in any effort to validate individual tests, as each test helps to cross-check the others.

\section{ACKNOWLEDGMENTS}

This work was supported by the Office of Building Technologies, State and Community Programs (BTS) of the U.S. Department of Energy, for which I am grateful. I thank Esher Kweller of BTS for his support and encouragement over the years. I thank Paul Francisco of Ecotope, Inc. and Jim Cummings of the Florida Solar Energy Center for their cooperation in publishing sufficient data from their projects to enable the comparisons in this report.

\section{REFERENCES}

Andrews, J.W., R.L. Hedrick, M.R. Lubliner, B.P. Reid, B.L. Pierce, and D.W. Saum. 1998. Reproducibility of ASHRAE Standard 152P: Results of a Round-Robin Test. ASHRAE Transactions V. 104, Pt. 1B, pp. 1376-1388.

Andrews, J.W. 1998. Error Reduction in Duct Leakage Testing Through Data Cross-Checks. BNL-66147, December.

Andrews, J.W. 2000. Measurement Uncertainties in the Delta Q Test for Duct Leakage. Brookhaven National Laboratory report in preparation.

ASHRAE 1999. Standard 152P: Method of Test for Determining the Design and Seasonal Efficiencies of Residential Thermal Distribution Systems. American Society of Heating, Refrigerating, and Air-Conditioning Engineers, Inc., Atlanta, GA. May.

Cummings, J.B. and C.R.Withers. 1999. Assessment of the Duct Leakage Estimation Procedures of the Standard and Alternative Test Methodologies of ASHRAE 152P. FSEC-CR-1135-99.

December.

Francisco, P.W. and Palmiter, L. 1999. Field Validation of ASHRAE Standard 152. Ecotope, Inc., Seattle, WA. ASHRAE Project 1056-RP Final Report. October. 

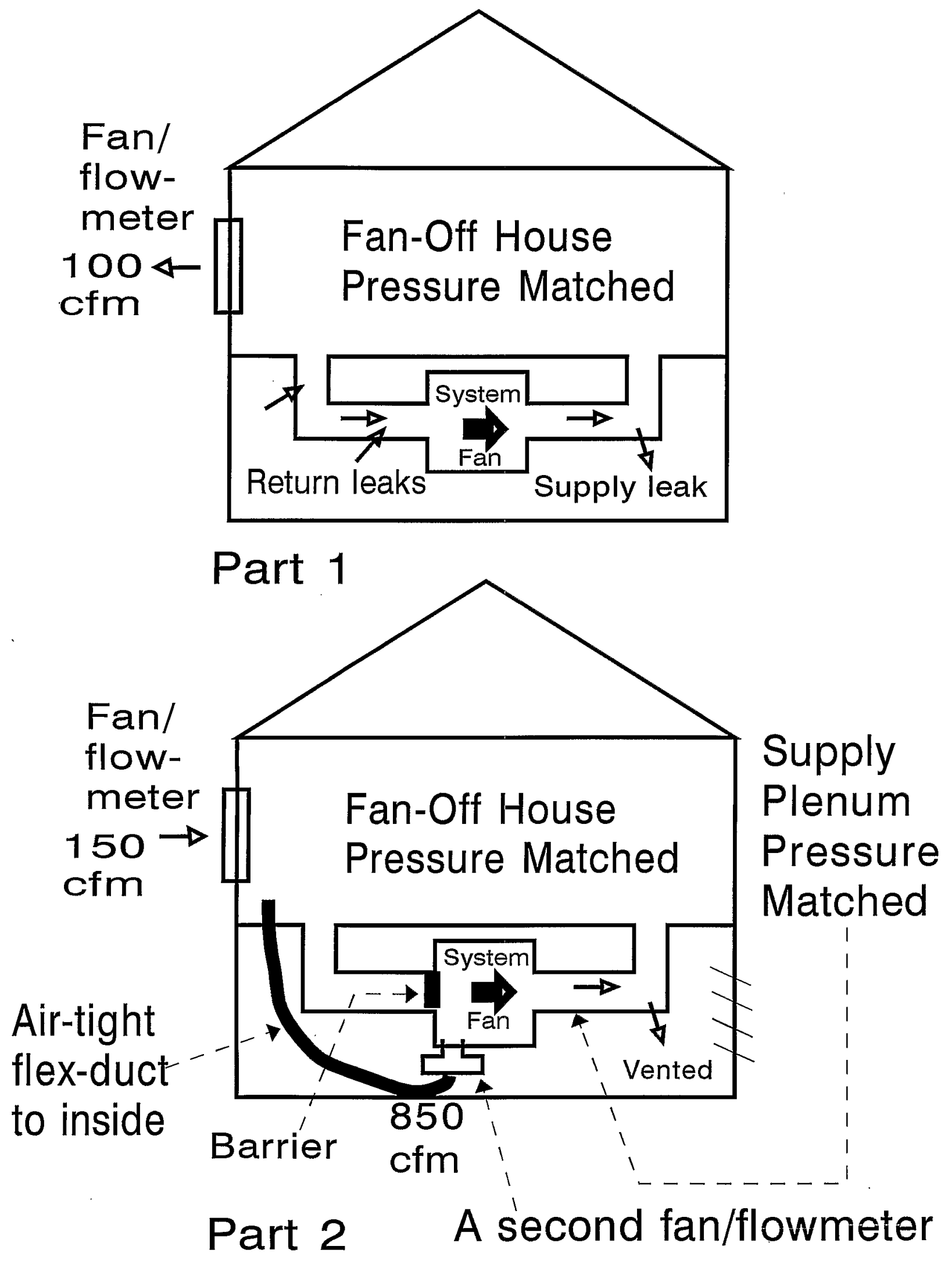

Figure 1. Schematic of Nulling Test Setup. 